\title{
Análise da evolução tectonossedimentar da Bacia dos Parecis através de métodos potenciais
}

\author{
Ruy Benedito Calliari Bahia ${ }^{1}$,Marcelo A. Martins-Neto ${ }^{2}$, Maria Silvia C. Barbosa ${ }^{3}$ \\ \& Augusto José Pedreira ${ }^{4}$
}

\begin{abstract}
Resumo A intracratônica Bacia dos Parecis está localizada na região centro-oeste do Brasil, no setor sudoeste do Cráton Amazônico, recobrindo partes das províncias Sunsás, Rondônia-Juruena e Tapajós-Parima (Santos 2002). Após os trabalhos de Teixeira (1993) e Siqueira (1989), embasados em dados geofísicos e geológicos, a bacia foi dividida, de oeste para leste, em três domínios tectono-sedimentares: o extremo oeste, uma depressão tectônica ( Fossa Tectônica de Rondônia); a porção central, um baixo gravimétrico e o extremo leste, uma bacia interior denominada por Schobbenhaus (1984) de Bacia do Alto Xingú. Durante o Ordoviciano até o Eo-Permiano, a região Amazônica foi afetada por um evento extensional, quando foram depositados os sedimentos ordovicianos da Formação Cacoal, representando o registro do estágio rifte da Bacia dos Parecis. Do Devoniano ao Eo-Permiano as formações Furnas, Ponta Grossa, Pimenta Bueno e Fazenda da Casa Branca foram depositadas durante o estágio sag da bacia. Durante o Mesozóico (Triássico ao Cretáceo) uma sucessão de rochas vulcânicas e sedimentares representa outro evento extensional . Este evento está representado na Bacia dos Parecis pelos arenitos eólicos da Formação Rio Ávila e os derrames basálticos das formações Anarí e Tapirapuã. O Grupo Parecis, composto de conglomerados e arenitos, representa o estágio deposicional relacionado ao Cretáceo. Os dados gravimétricos e magnéticos da Bacia dos Parecis foram adquiridos pelo IBGE, PETROBRAS e CPRM. O mapa gravimétrico da Bacia dos Parecis obtido através do software Oásis/Geosoft mostra uma extensa anomalia Bouguer negativa que se destaca no interior do Cráton Amazônico, com desvio do campo regional da ordem de $-40 \mathrm{mgl}$. O trend estrutural regional de direção leste-oeste, com desvio do campo regional da ordem de 80 mgal, evidencia o prosseguimento dos grabens de Pimenta Bueno e Colorado, os quais compõem a Fossa Tectônica de Rondônia, por baixo da seqüência mesozóica. A existência dessa estrutura é sustentada pelo mapa da Deconvolução de Euler, obtido através de um processo de inversão, a qual segue uma estimativa da profundidade da anomalia relacionada ao embasamento cristalino.
\end{abstract}

Palavras-chave: Bacia dos Parecis, estratigrafia, tectônica, geofísica.

\begin{abstract}
Analysis of evolution of Parecis Basin through potential methods. The Parecis basin is located in central-western Brazil, on the southwestern part of the Amazon Craton, partially covering the Sunsás, Rondônia-Juruena and Tapajós-Parima provinces (Santos 2002). Based on Teixeira (1993) and Siqueira (1989), the Parecis basin was divided, from west to east, into three tectono-sedimentary domains: the Rondônia tectonic, the central compartment ( negative gravimetric anomaly) and a interior sag (Alto Xingu basin). During the Ordovician to Early Permian, the eastern Amazon region was affected by an extensional event and the Cacoal formation was deposited (rift stage of the Parecis basin). From Devonian to Early Permian, Furnas, Ponta Grossa, Pimenta Bueno and Fazenda da Casa Branca formations were deposited during the sag stage of the basin. Mesozoic (Late Triassic to Cretaceous) volcanic and sedimentary successions record another extensional event in the Amazon region. This event is represented in the Parecis basin by the eolian sandstones of the Rio Ávila Formation and the basalts of the Anarí and Tapirapuã formations. The Cretaceous depositional stage is represented by the Parecis Group. Gravity and magnetic data of the Parecis basin have been acquired by IBGE, PETROBRAS and CPRM. Gravimetry and magnetometry maps obtained through the use of the Oasis/Geosoft software show an extensive negative anomaly in the interior of the Amazon Craton, with an average deviation from regional field of $-40 \mathrm{mgal}$. The east-west regional structural trend with a deviation from regional field of -80 mgal evidences the eastward continuity of Pimenta Bueno and Colorado grabens underneath the Mesozoic succession (Rondônia tectonic low). The existence of this structure is supported by the Euler Deconvolution map, obtained through an inversion procedure that allowed an estimation of the anomaly (basement) depth.
\end{abstract}

Keywords: Parecis basin, estratigraphy, tectonics, geofisics.

1 - CPRM/REPO - Serviço Geológico do Brasil, Porto Velho (RO), Brasil. E-mail: ruybahia@pv.cprm.gov.br

2 - Depto. Geologia, Universidade Federal de Ouro Preto, Ouro Preto (MG), Brasil..E-mail: marcelo@nupetro.com.br

3 - Depto. Geologia, Universidade Federal de Ouro Preto, Ouro Preto (MG), Brasil E-mail: silvia@nupetro.com.br

4 - CPRM/SUREG-SA - Serviço Geológico do Brasil, Salvador (BA), Brasil. E-mail: ajpedreira@terra.com.br. 
INTRODUÇÃO O presente trabalho é uma primeira tentativa de registrar a evolução tectonossedimentar da Bacia dos Parecis a partir de dados geofísicos. A nomenclatura estratigráfica segue aquela apresentada por Siqueira (1989), enquanto que e a descrição e interpretação das várias unidades litoestratigráficas estão baseadas nos diversos trabalhos prévios, bem como em novos dados coletados e tratados pelos autores.

A Bacia dos Parecis é uma das maiores bacias intracratônicas brasileiras. Localiza-se nas regiões Amazônica e Centro Oeste do Brasil, entre as bacias do Solimões, Alto Tapajós e Paraná, na região de antepaís da Cordilheira dos Andes (Figs. 1A e 1B). A bacia cobre uma área de $500.000 \mathrm{~km} 2$ nos estados de Rondônia e Mato Grosso, acumulando mais de $6000 \mathrm{~m}$ de sedimentos paleozóicos, mesozóicos e cenozóicos, essencialmente siliciclásticos. Tectonicamente ocupa setor sudoeste do Cráton Amazônico, entre os cinturões de cisalhamento Rondônia e Guaporé. Os limites sudeste e nordeste da bacia são os arcos do Xingu (Almeida 1983) e Rio Guaporé, respectivamente.

GEOLOGIA O mapeamento geológico da bacia ao nível de reconhecimento (escala 1:250.000), foi realizado na década de 70 pelo Departamento Nacional da Produção Mineral - DNPM, em convênio com a Companhia de Pesquisa de Recursos Minerais - CPRM, através da execução dos seguintes projetos: as porções oeste da bacia pelo Projeto Sudeste de Rondônia (Pinto Filho et al.,1977), a central e a nordeste pelo Projeto Centro-Oeste do Mato Grosso (Padilha et al.,1974), a sudoeste pelo Projeto Serra do Roncador (Costa et al.,1975) e a cunha sudeste da bacia pelos projetos Alto Guaporé e Serra Azul (Barros \& Pastore Jr.,1974 e Ribeiro Filho et al.,1975, respectivamente). Siqueira (1989) integrou as informações dos mapeamentos geológicos com dados de geofísica obtidos por outros autores, publicando uma síntese sobre a Bacia dos Parecis. Após os trabalhos de campo desenvolvidos durante esta pesquisa, foi possível elaborar o mapa geológico da bacia (Fig. 2).

O embasamento da Bacia dos Parecis é o Cráton Amazônico. Ele compreende rochas metamórficas de alto e baixo grau, bem como rochas intrusivas. As primeiras incluem os granulitos do Complexo Jamarí (oeste da bacia, em Rondônia) e os gnaisses, migmatitos e granitóides arqueanos e mesoproterozóicos do Complexo Xingu (norte e sul da bacia, no Mato Grosso e Goiás). As rochas metassedimentares (sudeste da bacia, em Mato Grosso e Goiás). As rochas intrusivas são básicas e ultrabásicas e de idade mesozóica (Fig. 3). Recentemente, Marzoli et al. (1999) dataram os basaltos das formações Anari e Tapirapuã em $198 \mathrm{Ma} \mathrm{(Ar/}$ Ar), idade que se aproxima daquela determinada por Pinto Filho (1977) de 208+14Ma. (métodoK/Ar), para a Formação Anari.

As rochas sedimentares da bacia, depositadas em ambiente continental (desértico, fluvial, lacustre e glacial) e marinho raso, são ricas em matéria orgânica, fato que levou a PETROBRAS a explorar hidrocarbonetos na bacia. Entretanto somente dois furos de sonda foram executados: o primeiro pela CPRM, para pesquisa de carvão energético, e o segundo pela PETROBRAS, para hidrocarbonetos.

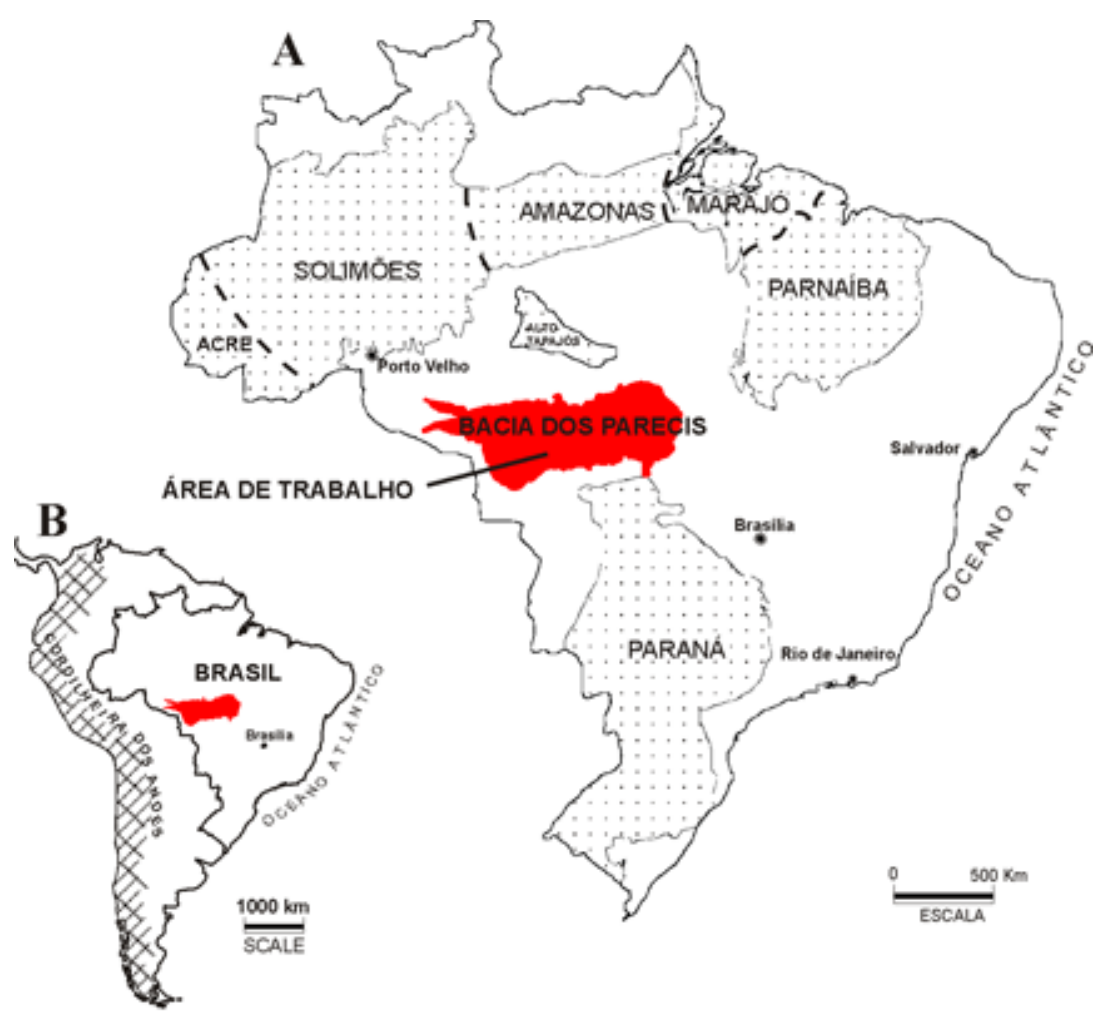

Figura 1 - Mapa de localização da Bacia dos Parecis. 


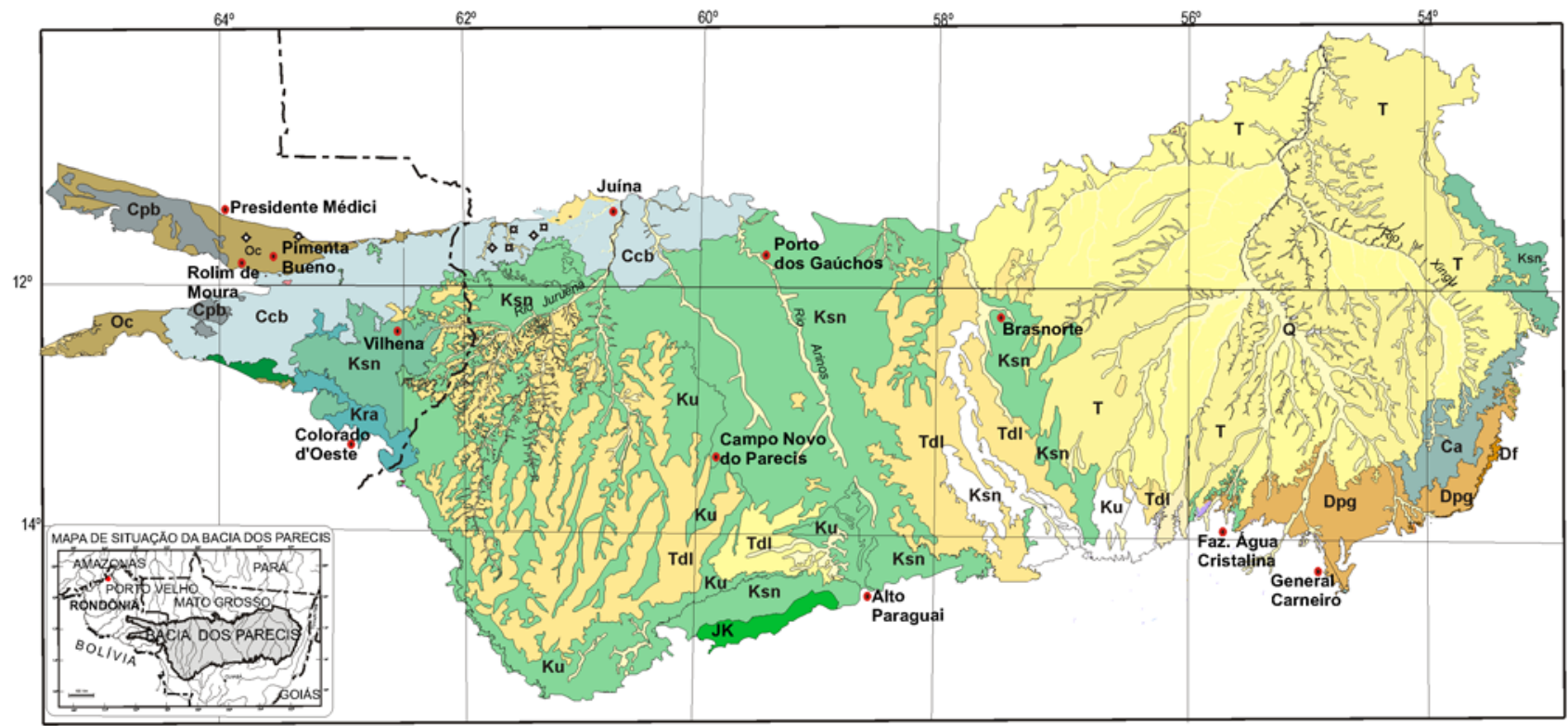

\section{Q Aluvião \\ $T$ Cobertura terciária \\ Cretáceo}

Ku Formação Utiariti : conglomerados, arenitos, pelitos Ksn Formação Salto das Nuvens: conglomerados Jurássico-Cretáceo

JK Formações Anari (a) \& Tapirapuã (t): basaltos e diabásios Jra Formação Rio Ávila: arenitos eólicos

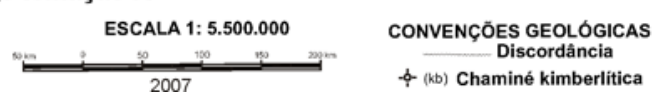

\section{Permiano-Carbonífero}

Ca Formação Aquidauana: arenito, conglomerado e siltito.

Ccb Formação Fazenda da Casa Branca: conglomerado, arenito e argilito.

Cpђ Formação Pimenta Bueno: conglomerado, arenito, folhelho, clastos caídos. Devoniano

Dpg Formação Ponta Grossa: arenito, siltito e folhelho.

Df Formação Furnas: arenito

Ordoviciano

Oc Formação Cacoal; conglomerado, arcóseo, arenito, folhelho e calcário.

Figura 2 - Mapa geológico da Bacia dos Parecis. (mapa colorido disponível na versão on-line)

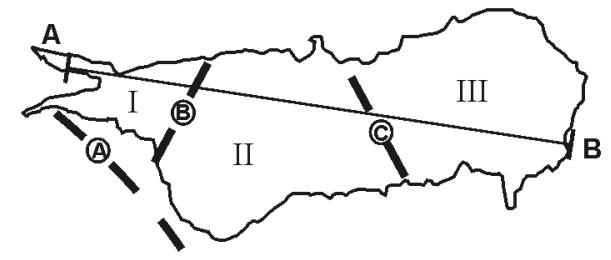

(B)

B

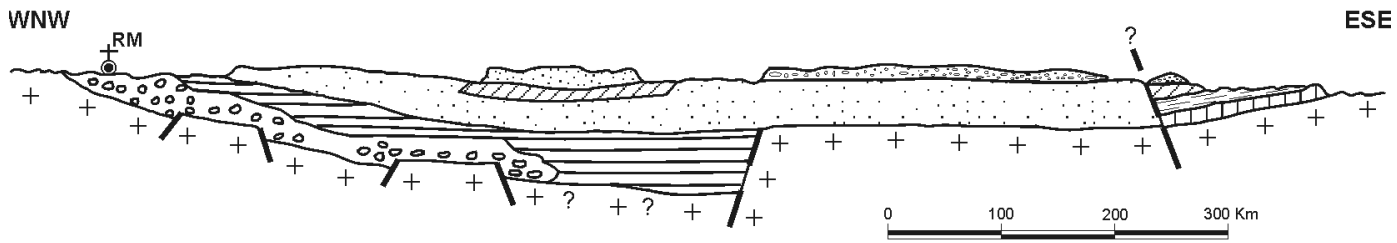

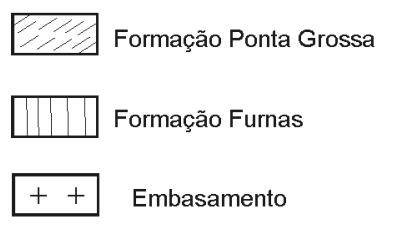

(A) Arco do Rio Branco do Guaporé

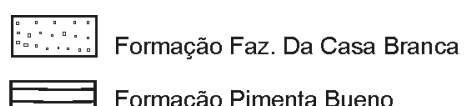

Formação Pimenta Bueno

\%89: Formação Cacoal

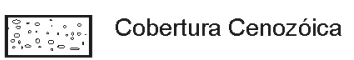

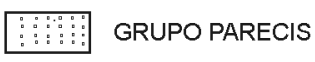

ZC. Formação Rio Ávila

Figura 3 - Seção esquemática da Bacia dos Parecis mostrando os domínios tectono-sedimentares e os arcos do embasamento. Convenções: 1 - Limites aproximados dos domínios tectono-sedimentares: I - Fossa Tectônica de Rondônia; II - Baixo Gravimétrico dos Parecis; III Depressão do Alto Xingú; 2 - Arcos: A - Rio Branco do Guaporé; B-Rio Xingu; C-Serra Formosa. 
A evolução tectonossedimentar da bacia ou de partes dela foi esboçada em trabalhos anteriores (Siqueira, 1989; Bahia \& Pedreira, 1996; e Bahia et al.1996). No presente trabalho esta evolução é analisada através de métodos potenciais, que permitem o estudo da bacia em subsuperfície.

GEOFÍSICA A Bacia dos Parecis, encontra-se totalmente coberta por levantamentos regionais geofísicos através de métodos potenciais, realizados pela PETROBRAS, CPRM E IBGE (Fig 4).

Apesar de vasta área de difícil acesso, coberta por florestas e reservas indígenas, essas restrições foram superadas pelos levantamentos aerogravimétricos e aeromagnéticos, que cobrindo toda a área da bacia, e fornecem um conjunto de dados facilmente tratáveis pelas modernas técnicas de interpretação. Em locais de fácil acesso foram realizadas linhas sísmicas de reconhecimento e gravimetria terrestre que permitiram a primeira visualização da sismoestratigrafia da bacia (Teixeira et al. 1993) e motivaram a perfuração pela PETROBRAS do primeiro poço (2-FI-1-MT) exploratório para hidrocarbonetos.

GRAVIMETRIA Os dados gravimétricos da Bacia dos Parecis foram coletados pelo IBGE e PETROBRAS, conforme está mostrado na figura 4. Segundo Siqueira (1989), a Bacia dos Parecis corresponde à única grande anomalia Bouguer negativa destacada no interior do Cráton Amazônico, com desvio do campo regional da ordem de $-40 \mathrm{mgal}$, a qual ele denominou de Baixo Gravimétrico dos Parecis. Nos locais de fácil acesso, como é o caso da Fossa Tectônica de Rondônia, o levantamento gravimétrico foi executado por via terrestre.

O levantamento gravimétrico, por ter sido realizado por dois órgãos diferentes e com objetivos distintos, não apresenta uma distribuição homogênea dos dados. A gravimetria terrestre foi realizada apenas ao longo das rodovias, com maior concentração na porção central. O espaçamento das medidas é diferente ao longo dos perfis.

O levantamento aerogravimétrico da Bacia dos Parecis foi realizado pela PETROBRAS em 1988 e cobriu as porções leste, na Sub-bacia Juruena, e posteriormente, foi estendido para oeste e sudeste da bacia, até a Sub-Bacia Alto Xingu.. O espaçamento das linhas de vôo foi de $6 \mathrm{~km}$, com direção N150W, e com linhas de controle separadas de $6 \mathrm{~km}$ na direção N750E, com altura de vôo de 1000 metros. O gravímetro utilizado foi do tipo LaCoste \& Romberg ZLS, montado em plataforma estabilizadora tri-axial. A navegação e o posicionamento planialtimétrico foram controlados com uso de GPS, altímetros e barômetros (Marinho 1995).

O mapa de anomalia Bouguer foi obtido através da interpolação dos dados aéreos e terrestres, feita pelo programa Oasis da Geosoft. Latitudes e longitudes foram convertidas para as coordenadas X e Y, usando a projeção Lambert.

Uma análise inicial do mapa gravimétrico da Bacia dos Parecis (Fig. 5), indica a assinatura geométrica das principais falhas da bacia, a estrutura dos domínios geológicos e a localização dos principais depocentros da bacia. Observam-se nitidamente dois baixos gravimétricos a norte e no centro-oeste da bacia, separados por um alto estrutural com direção leste-oeste, confirmando o trend regional das estruturas. Estes baixos gravimétricos, com desvio do campo regional da ordem de 80 mgal, são coincidentes com o prosseguimento dos grabens de Pimenta Bueno e Colorado, por baixo da seqüência mesozóica, relacionados com a fase rifte, precursora da bacia.

Os lineamentos indicados no mapa gravimétrico, têm correlação com as falhas Itapuã e Presidente Médici, mapeadas durante o Projeto Sudeste de Rondônia (Pinto Filho et al, 1977). Estas falhas foram geradas no embasamento cristalino durante a formação da Província Rio Negro-Juruena (Tassinari \& Macambira,

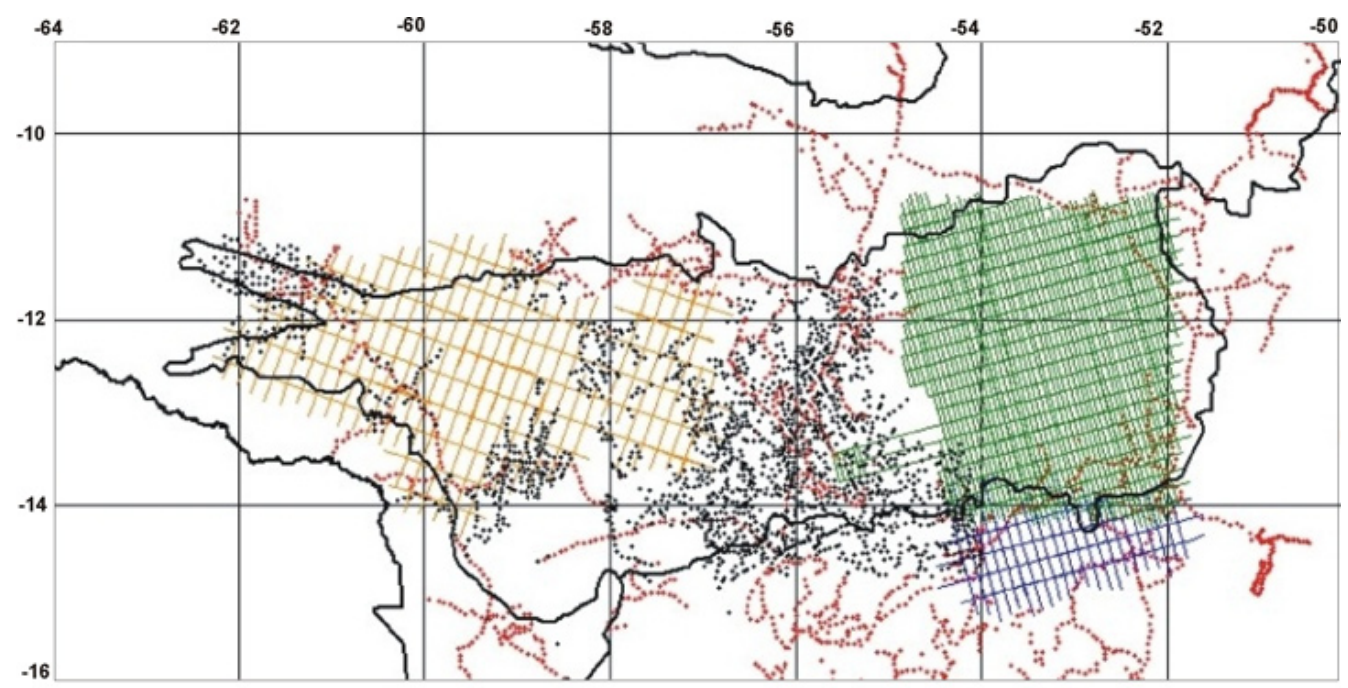

Figura 4 - Mapa Base dos levantamentos gravimétricos e magnéticos da Bacia dos Parecis. 
1999) e reativadas como falhas normais durante a abertura do Oceano Atlântico. Neste mapa está bem definida a Sub-Bacia do Xingu de Siqueira(1989), com dois depocentros a NW e SE do rio Xingu, separadas por um alto estrutural denominado de Alto do Rio Xingu.

Observando o Mapa da Segunda Derivada Vertical do campo gravitacional da Bacia dos Parecis (Fig. 6), nota-se uma perfeita seqüência de altos e baixos estruturais, numa configuração grabens-horsts, definindo os depocentros da bacia, alinhados segundo uma estruturação NW-SE. São destacados quatro eixos anômalos positivos, cujas direções principais são coerentes com a estruturação da bacia, correspondendo aos grabens do Colorado, Pimenta Bueno, noroeste do Rio Xingu e su- doeste do Rio Xingu.

A continuidade para leste dos lineamentos que limitam os grabens de Pimenta Bueno e Colorado, os quais constituem a Fossa Tectônica de Rondônia, fortalece a hipótese de uma evolução da Bacia dos Parecis, do Ordoviciano ao Permiano, a partir de um rifte intracratônico (IF de Kingston et al,1983), passando conseqüentemente ao tipo sinéclise termal(IS de Kingston et al,1983), caracterizando a bacia como do tipo rifte-sag ou steer-head, conforme Dewey (1982).

MAGNETOMETRIA Os dados aeromagnéticos da porção ocidental da Bacia dos Parecis, mais precisamente na Sub-Bacia Juruena, apresentados através do

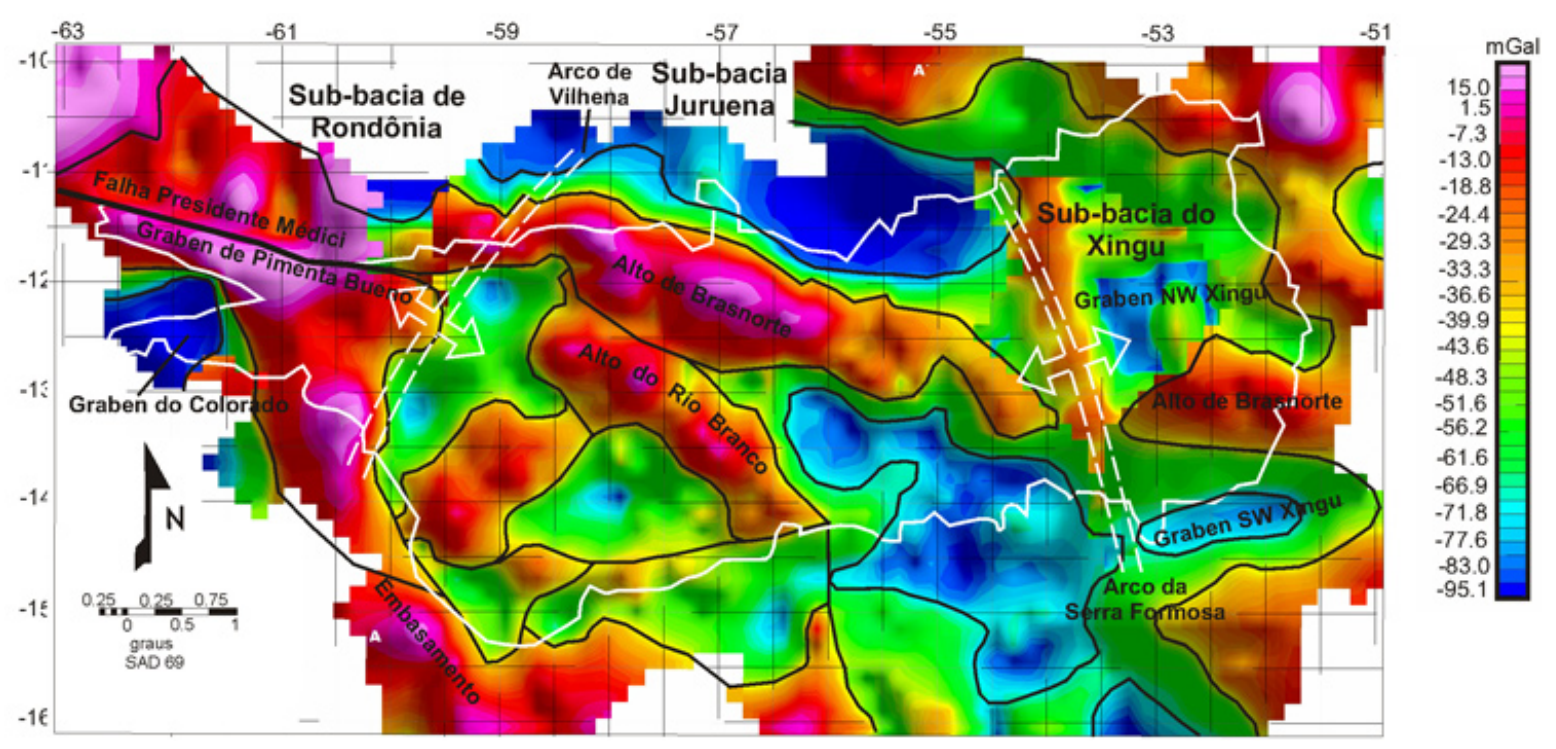

Figura 5 - Mapa gravimétrico Bouguer da Bacia dos Parecis.
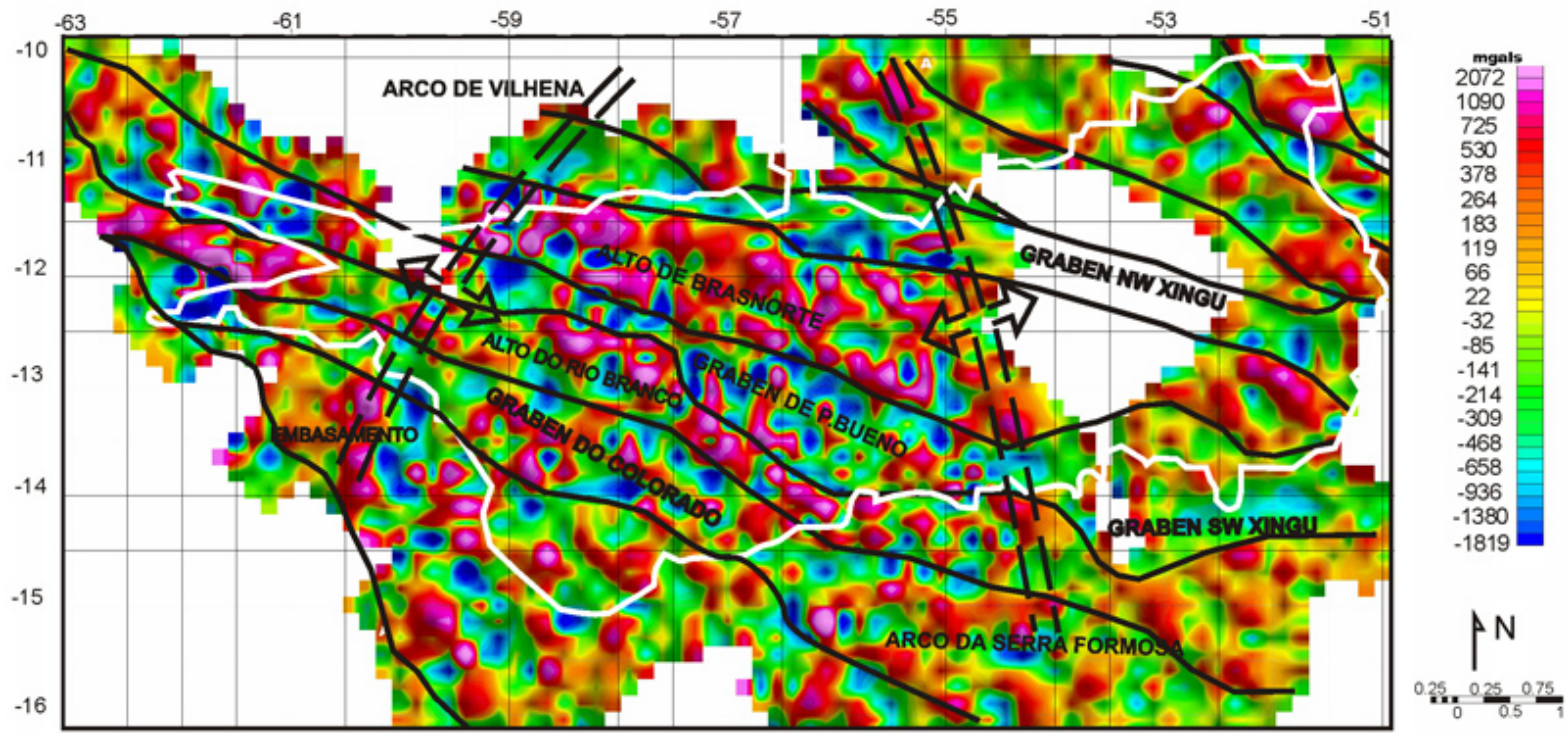

Figura 6-Mapa residual gravimétrico da Bacia dos Parecis. 
mapa magnético de campo total (Fig. 7), onde estão localizadas as maiores anomalias magnéticas negativas da Bacia dos Parecis, evidenciam o prosseguimento dos grabens de Pimenta Bueno e Colorado por mais de 700 $\mathrm{km}$ para leste, separados por um alto estrutural denominado de Alto do Rio Branco do Guaporé (Soeiro, et al, 1981), correspondendo a Fossa Tectônica de Rondônia de Siqueira (1989). Esta megaestrutura representa a fase rifte da evolução da Bacia dos Parecis, que juntamente com as sub-bacias do Juruena e do Alto Xingu, separadas pelo Arco da Serra Formosa, correspondem aos principais depocentros da bacia.

Nessas bacias estão instalados três sistemas de drenagem isolados, denominados de oeste para leste: Ji-Paraná, Alto Juruena e Alto Xingu, reforçando a existência dos referidos arcos (Siqueira \& Teixeira 1993). Esta hipótese foi proposta por Siqueira (1989), que defende o preenchimento da bacia por três seqüências sedimentares paleozóica, mesozóica e cenozóica, incluindo rochas vulcânicas do Cretáceo, com espessura aproximada de $6 \mathrm{~km}$.

Anomalias magnéticas negativas normalmente estão relacionadas a um adelgaçamento crustal, onde o aquecimento causado pela ascensão de material quente da astenosfera provoca a desmagnetização das rochas da crosta terrestre. Os baixos gravimétricos normalmente indicam a presença de uma espessa camada de rochas sedimentares, com densidade em torno de 2,6 g/ $\mathrm{cm} 3$, cobrindo as rochas mais densas da crosta terrestre, com densidade de $2,80 \mathrm{~g} / \mathrm{cm} 3$. Portanto, a integração dos mapas magnético e gravimétrico é importante para a confirmação da localização dos depocentros e altos estruturais no interior de uma bacia sedimentar.

$\mathrm{Na}$ integração dos lineamentos gravimétricos e magnéticos da Bacia dos Parecis (Fig. 8) confirma-se a presença dos depocentros indicados nos mapas magnético de campo total e gravimétrico, referente às subbacias do Juruena e do Alto Xingu, separadas pelo alto estrutural da Serra Formosa. É muito forte a estruturação na direção NW-SE, dos baixos gravimétricos e alto magnéticos, correspondente aos depocentros da bacia. Estes depocentros foram limitados posteriormente pelos altos estruturais de direção NE-SW. Observa-se também na figura 8 o prosseguimento para leste dos grabens de Pimenta Bueno e Colorado, desaparecendo por baixo das sub-bacias do Juruena e Alto Xingu. Este fato reforça a idéia da evolução da Bacia dos Parecis a partir de riftes intracontinentais passando para sinéclise termal. Estes depocentros foram subdivididos posteriormente pela elevação dos altos estruturais de direção NE-SW no interior da bacia, reflexo de uma tectônica modificadora provocada por processos ligados à evolução da Cordilheira dos Andes. A evolução da Bacia dos Parecis foi influenciada, desde o Paleozóico, pela elevação da Cordilheira dos Andes. Este fato é conseqüência de colisões na região andina que se manifestam também em outras bacias brasileiras, como as transcorrências na Bacia do Solimões (Siqueira 1993).

A deconvolução de Euler, outro método utilizado, refere-se a um procedimento de inversão que visa obter uma estimativa da profundidade do topo do corpo geológico que gera a anomalia gravimétrica ou magnética. Aplicou-se esta inversão nos dados magnéticos através do uso do software da Geosoft S.A. (Euler 3D)
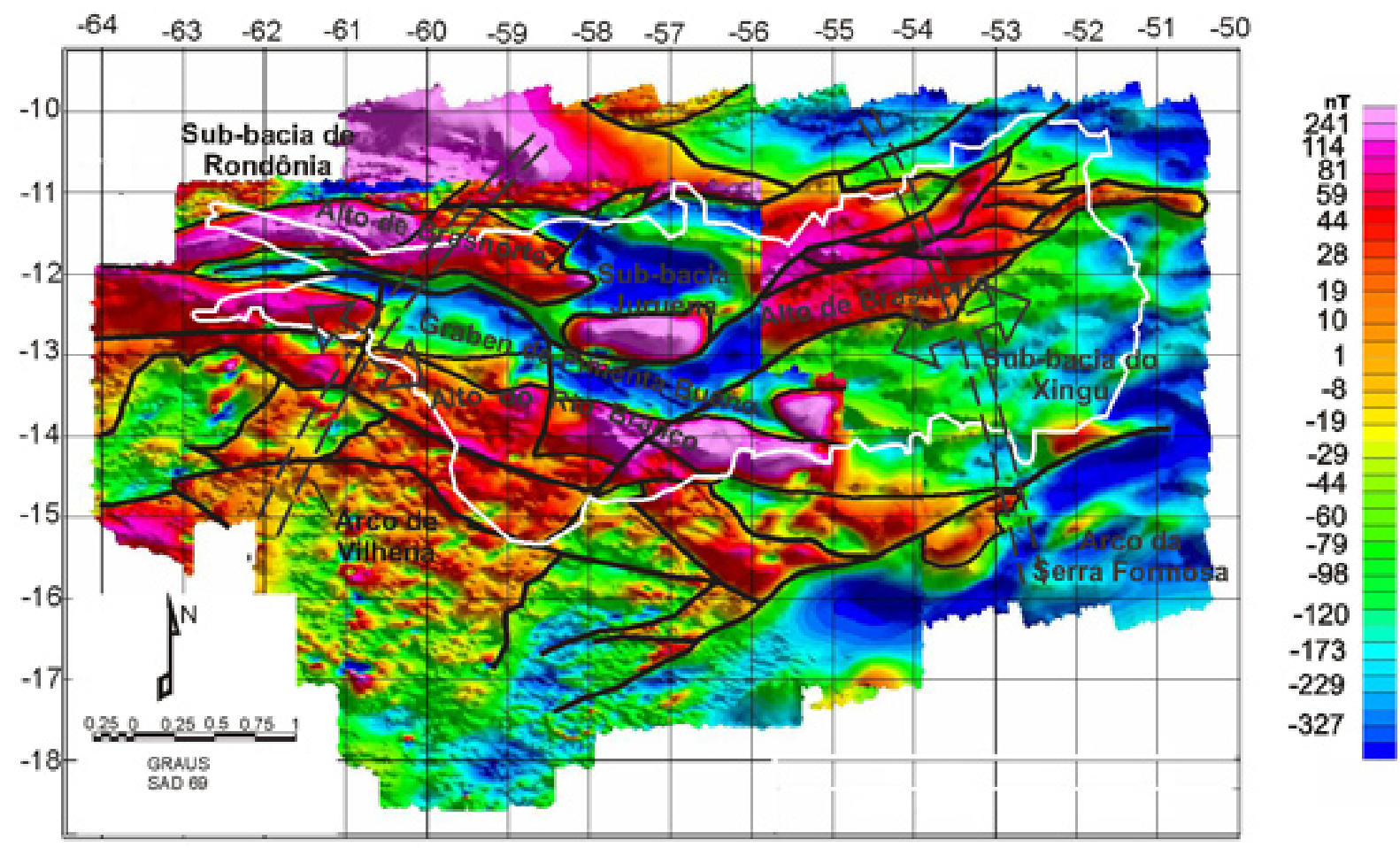

Figura 7 - Mapa magnético do Campo Total da Bacia dos Parecis. 
e, assim, estimou-se a profundidade do embasamento cristalino da Bacia dos Parecis (Fig. 9).

Nesta figura observa-se que as maiores profundidades do embasamento, indicadas pelos pontos com tonalidades mais avermelhadas, estão localizadas nas porções norte, central e leste da bacia, formando uma faixa com direção E-W com inflexão para SE, chegando próximo aos $6 \mathrm{~km}$ de profundidade. Esta faixa corresponde grosseiramente aos grabens de Pimenta Bueno e Colorado, nas porções norte e oeste da bacia, passando para as sub-bacias Juruena e Alto Xingu nas porções central e leste, respectivamente. Isto confirma

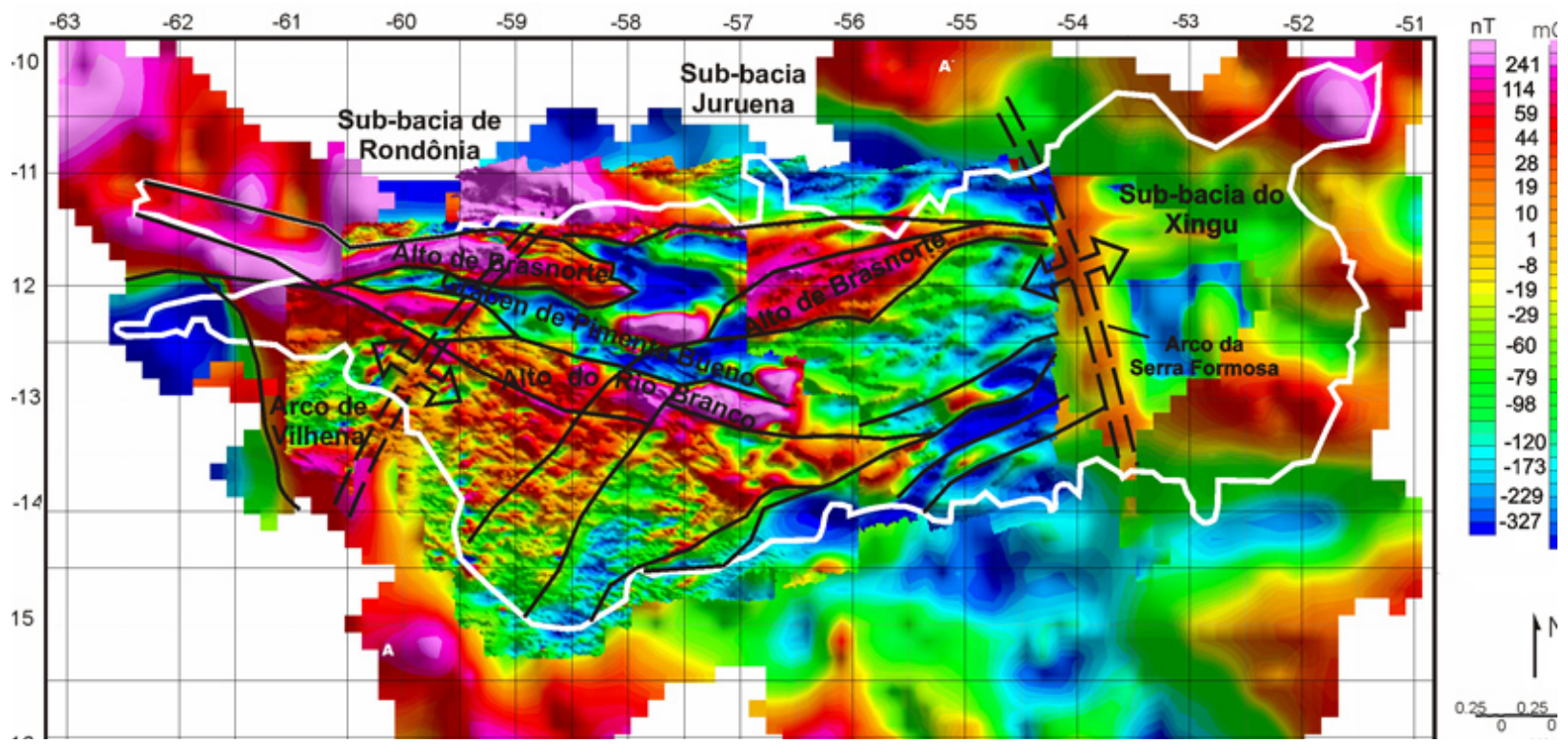

Figura 8 - Mapa Magnético com a integração dos lineamentos magnéticos e gravimétricos da Bacia dos Parecis.
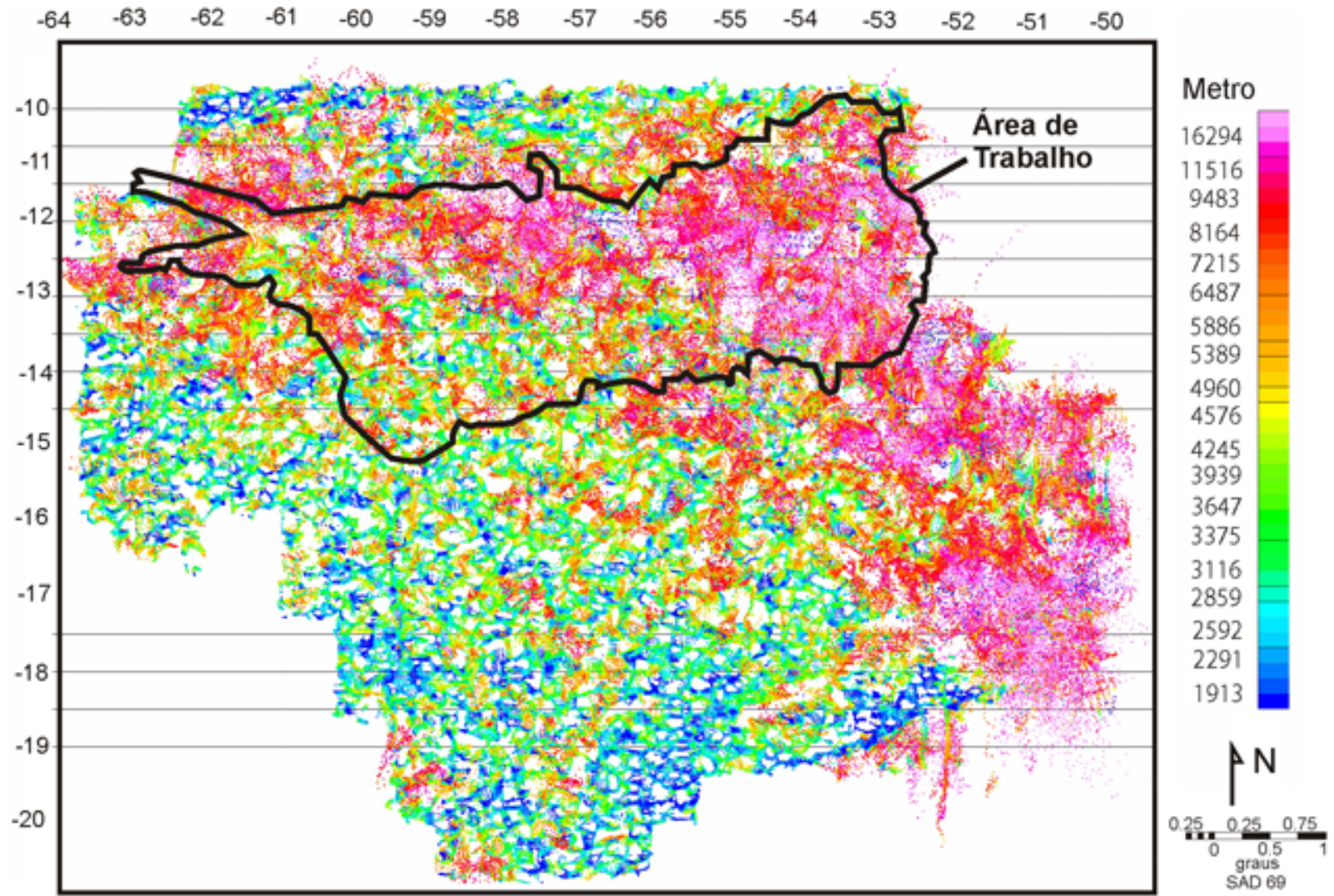

Figura 9 - Mapa da estimativa de profundidade do embasamento através da deconvolução de Euler-3D. 
o que já havia sido mostrado em figuras anteriores, ou seja, a localização dos depocentros no interior da Bacia dos Parecis.

MODELAGEM GRAVIMÉTRICA Os dados gravimétricos podem ser usados para estudo de vários tipos de estruturas geológicas, variando em profundidade e tamanho desde blocos crustais profundos até pequenos corpos próximos da superfície. Em geral grandes anomalias gravimétricas estão relacionadas à mudanças na espessura da crosta terrestre ou a presença de grandes massas de densidade contrastante na escala regional. As bacias sedimentares, os grabens, intrusões graníticas e domos salinos normalmente provocam uma anomalia gravimétrica negativa. Portanto, os dados gravimétricos são usados para a elaboração do modelamento tectônico e arquitetura geral de uma província tectônica, assim como de uma bacia sedimentar, a exemplo do trabalho de Vidotti (1998), no qual é apresentada uma revisão da evolução tectônica e geológica da Bacia do Paraná, com base em novos dados gravimétricos.

A modelagem tectônica foi elaborada através de três perfis idealizados com base nas principais feições tectônicas da bacia. Estão apresentados no mapa gravimétrico terrestre (Fig. 10), no qual os perfis foram posicionados transversalmente às anomalias Bouguer negativas, indicativas dos principais depocentros da bacia, com desvio de campo da ordem de -40 mgal. Esta anomalia reflete uma espessura da camada sedimentar, que pode atingir até $6 \mathrm{~km}$ nos principais depocentros (Fig. 11).

Para execução dos perfis foi considerada a profundidade de $35 \mathrm{~km}$ para a descontinuidade de Moho, uma densidade de $2,8 \mathrm{~g} / \mathrm{cm} 3$ para o embasamento cristalino (densidade média da crosta continental) e uma variação exponencial com a profundidade para a densidade dos sedimentos.

Nos perfis 1 e 3 observa-se que as anomalias negativas, da ordem de $75 \mathrm{mgls}$, são coincidentes com as sub-bacias do Juruena e Alto Xingu, com depocentros bem definidos e profundidades atingindo a marca dos $6 \mathrm{~km}$. Esses depocentros estão preenchidos por três seqüências sedimentares, separadas por discordâncias regionais relacionadas ao Paleozóico, Mesozóico e Cenozóico. A seqüência paleozóica bordeja a Bacia dos Parecis nos extremos oeste, sudeste e sudoeste, enquanto que a seqüência mesozóica ocupa as porções central e oeste da bacia e finalmente, a seqüência cenozóica se concentra principalmente na Sub-bacia Alto Xingu, formando o já conhecido "espanador" do Rio Xingu.

A modelagem gravimétrica na Bacia dos Parecis forneceu resultados interessantes sobre a arquitetura crustal na região da bacia. As seções crustais apresentadas na figura 9, onde a descontinuidade de Moho atinge $40 \mathrm{~km}$ de profundidade, permitiram verificar a configuração da descontinuidade de Moho. Esta configuração caracteriza um acamadamento espacial típico de uma crosta interior rifteada, coberta por uma espessa camada sedimentar nesta zona. No restante da bacia a interface crosta-manto apresenta-se levemente ondulada, com profundidade média em torno de $30 \mathrm{~km}$. Esta configuração deve-se possivelmente ao afinamento crustal/ litosférico e elevação da astenosfera, conseqüentes dos processos de rifteamento.

A EVOLUÇÃo DA BACIA O embasamento da Bacia dos Parecis é composto por rochas do Cráton Amazônico, formado por acreção através da colagem dos cinturões de cisalhamento Rio Negro-Juruena e Sunsas-Aguapeí, durante o Ciclo Transamazônico de idade paleoproterozóica (Brito Neves, 1995). Este cráton supostamente é um fragmento do Laurentia, e teria sido uma grande placa continental que foi acrecionada às partes central e sudeste do Continente Sul-americano (Brito Neves \& Cordani, 1991).

No setor sudoeste do Cráton Amazônico pro-

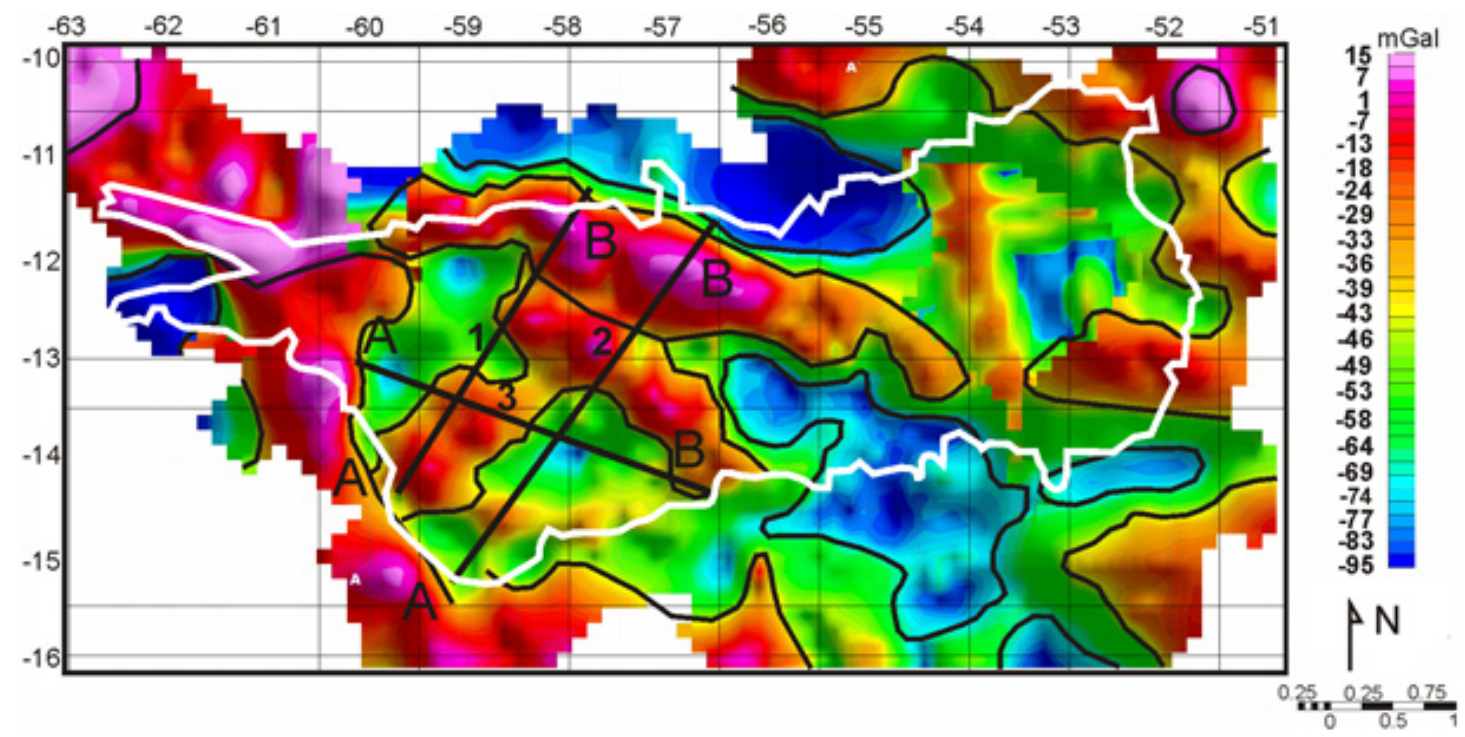

Figura 10 - Localização dos perfis gravimétricos modelados na Bacia dos Parecis. 

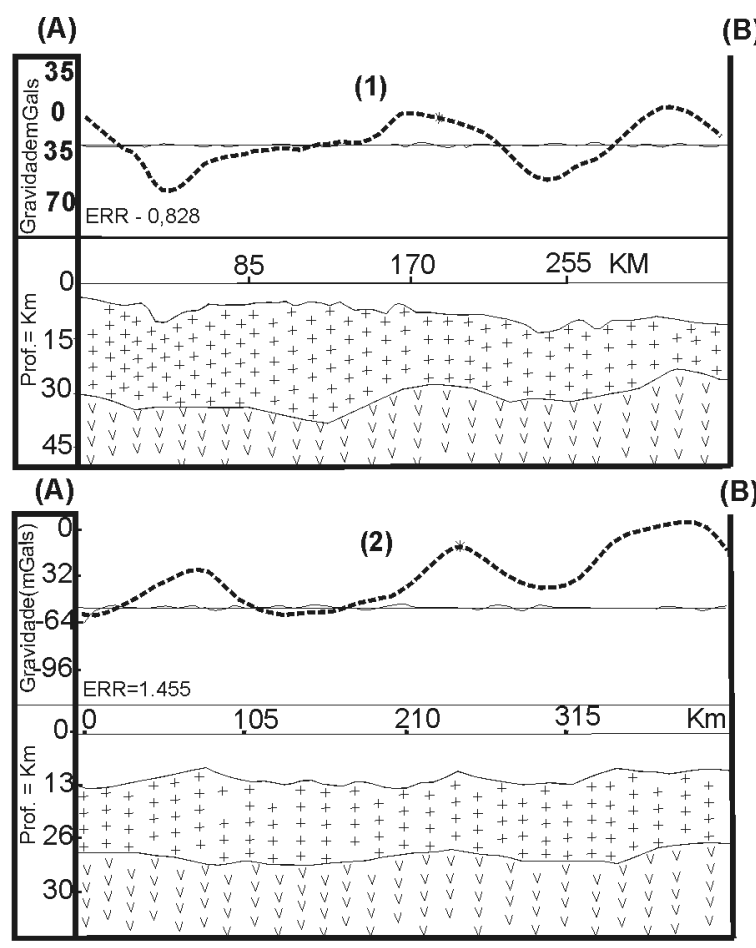

(A)

(B)

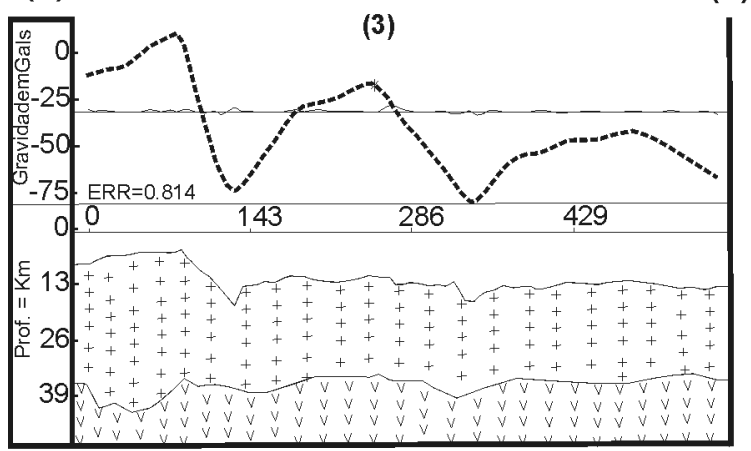

Figura 11 - Perfis gravimétricos modelados na Bacia dos Parecis, apresentando a camada sedimentar, sobre o embasamento cristalino. cessos tectônicos intraplaca durante o Paleozóico, tiveram como resultado a formação das grandes bacias sedimentares do Solimões e Amazonas (ver Fig. 1), além da Bacia dos Parecis, objeto deste estudo, as quais foram preenchidas por seqüências sedimentares continentais e marinhas, fortemente controladas por estruturas do embasamento (Brito Neves et al. 1984).

A Bacia dos Parecis foi dividida por Siqueira (1989) em três domínios tectono-sedimentares: 1) A Fossa Tectônica de Rondônia (Sub-bacia de Rondônia), no oeste da bacia; 2) O Baixo Gravimétrico dos Parecis (Sub-bacia do Juruena), sudoeste da bacia; e 3) A Depressão do Alto Xingu (Sub-bacia do Alto Xingu), no limite leste da bacia (Fig. 12).

De acordo com os dados apresentados, a Bacia dos Parecis pode ser classificada como uma bacia do tipo rifte-sag. Sua evolução ocorreu a partir da Fossa Tectônica de Rondônia, uma bacia rifte localizada no domínio oeste da Bacia dos Parecis, cujos depósitos correspondem às formações Cacoal e Pimenta Bueno (Fig. 13).

Os dados gravimétricos sugerem a continuidade desta depressão tectônica para sudeste, no Baixo Gravimétrico dos Parecis, ocupando a metade oeste da bacia. Este domínio é interpretado como uma transição para uma bacia tipo sinéclise termal, onde foram depositadas as formações Fazenda da Casa Branca e Rio Ávila e o Grupo Parecis.

O domínio leste da bacia, denominado de Depressão do Alto Xingu, representa o registro da fase sinéclise termal da bacia, que recebeu os sedimentos arenosos da Formação Furnas, passando gradativamente para os sedimentos pelíticos da Formação Ponta Grossa, sotopostos à Cobertura Cenozóica Inconsolidada, representando uma inundação progressiva da plataforma no Eodevoniano, atingindo o pico em $440 \mathrm{Ma}$, correspondendo a um ciclo transgressivo-regressivo, que na Bacia do Paraná constitui a Superseqüência Paraná

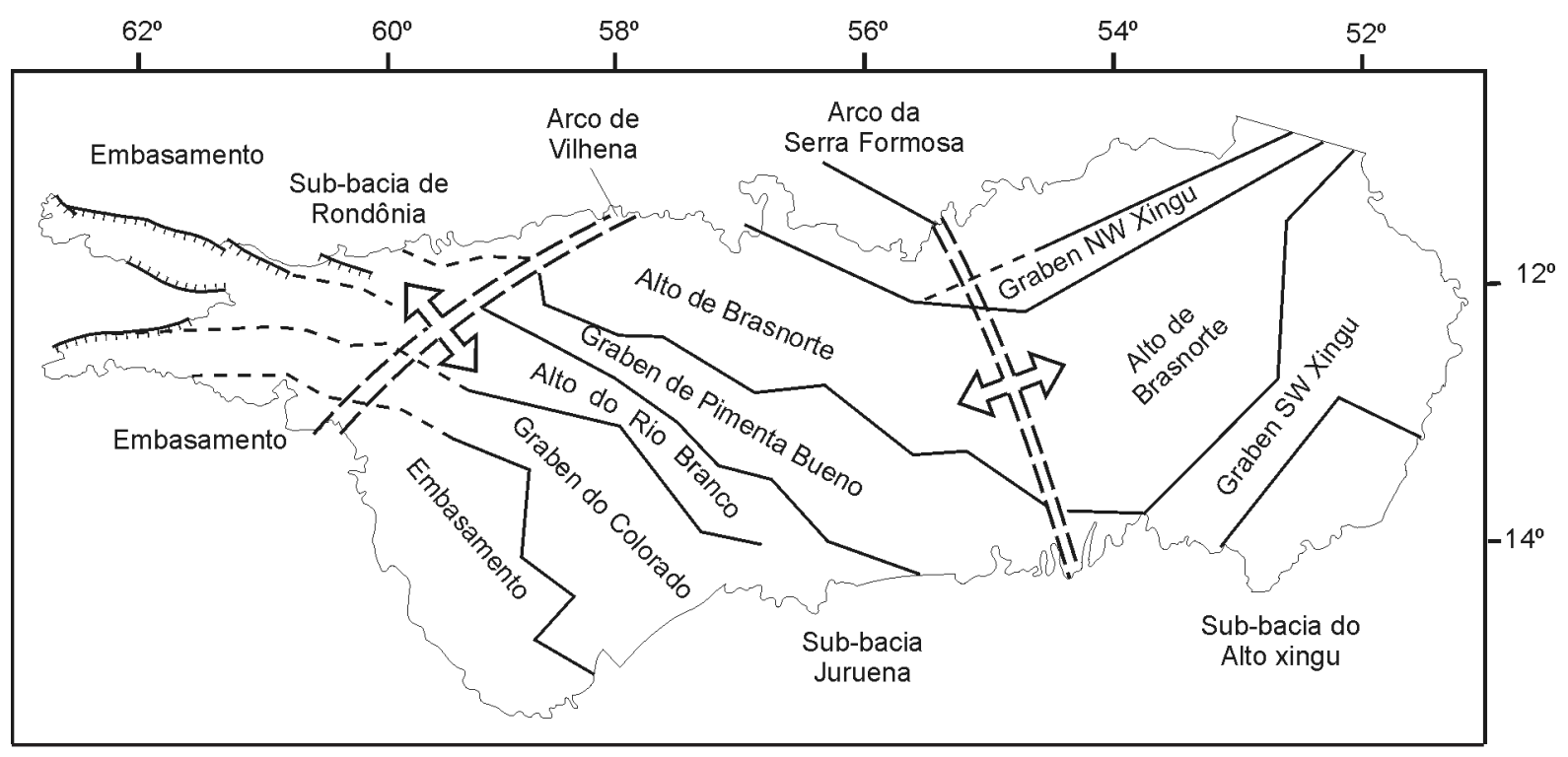

Figura 12 - Domínios tectônicos da Bacia dos Parecis (modificado de Siqueira 1989). 


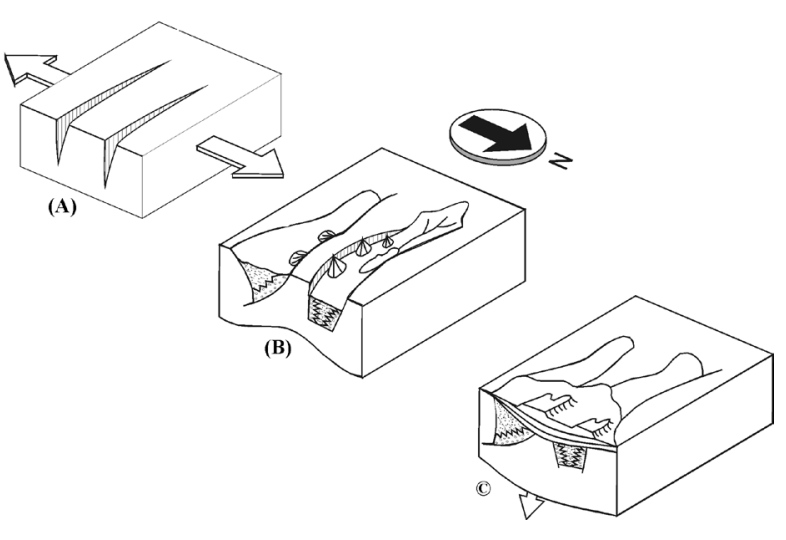

Figura 13 - Blocos diagramas mostrando a evolução da porção oeste da Bacia dos Parecis. (A) Tafrogênese: extensão no setor sudoeste do Cráton Amazônico formando os grabens de Pimenta Bueno e Colorado; ( B) Deposição das formações Cacoal e Pimenta Bueno no interior dos grabens; ( C) Koilogênese: final da fase rifte com subsidência regional e deposição das formações Fazenda da Casa Branca.Rop Ávila, Anari e Parecis.

de Milani (1997).

A passagem da fase rifte para a fase sinéclise da bacia, foi marcada por profundas modificações tectônicas e climáticas. Nessas condições foi depositada a Formação Pimenta Bueno (glaciogênica), durante a fase rifte e a Formação Fazenda da Casa Branca (fluvial/peri-glaciogênica), já na fase sinéclise. Estas unidades constituem o pacote permo-carbonífero da Bacia dos Parecis correlacionado com a Superseqüência Gondwana I de Milani (1997) na Bacia do Paraná.

Durante o Mesozóico, após um período erosivo sob condições de extrema aridez, refletindo em uma quebra no registro estratigráfico da Bacia dos Parecis, correspondendo a um período de intumescência da bacia, entre a orogênese Gonduanite e a Tectônica Juruá, a região Amazônica foi novamente afetada por outro evento extensional, provocando uma nova subsidência na bacia, compensada pela deposição de sedimentos eólicos e derrames de rochas vulcânicas alcalinas, em ambiente continental e clima árido, num amplo deserto gondwânico, relacionados às formações Rio Ávila e Anarí/Tapirapuã, respectivamente correlatas as formações Botucatu e Serra Geral, que constituem a Superseqüência Gondwana III de Milani (1997).

Prosseguindo com a subsidência da bacia até o Cretáceo, ocorre a deposição dos sedimentos fluviolacustres da Formação Parecis.

Não existem evidências de forte modificação da bacia por eventos tectônicos. Entretanto, durante o Cenozóico, o soerguimento da cordilheira andina (figura 1) teve reflexo na Bacia dos Parecis. Nesta época ocorreu o soerguimento do Arco do Rio Guaporé, que separa a bacia da Depressão Sub-Andina e a sedimentação cenozóica foi restringida à Bacia dos Parecis, sendo desenvolvida sobre uma crosta laterítica desmantelada pela erosão.

CONCLUSÕES O substrato da Bacia dos Parecis corresponde em grande parte ao cinturão móvel Rondônia-Juruena (Santos in Bizzi 2003) e uma pequena porção, a oeste, ao cinturão móvel Sunsás (Tassinari 1996), entidades geotectônicas formadas durante o Meso e Neoproterozóico Médio, respectivamente.

A implantação da bacia deu-se no Neo-Ordoviciano, quando a Região Amazônica foi afetada por um evento extensional, com a geração de um sistema de riftes intracontinentais, aproveitando zonas de fraqueza anteriores, os quais foram preenchidos pelo menos em parte pela Formação Cacoal. Sobre este sistema de riftes depositaram-se, do Devoniano ao Cretáceo, as formações Furnas, Ponta Grossa, Pimenta Bueno, Fazenda da Casa Branca, Rio Ávila e Grupo Parecis.

As unidades litoestratigráficas citadas formam cinco seqüências deposicionais: Ordoviciana, Devoniana, Carbonífero-permiana, Juro-cretácea e Cretácea, separadas por discordâncias regionais, com indicação de deposição em uma bacia tipo sinéclise de interior continental.

Durante o Mesozóico (Juro-cretáceo), a Região Amazônica foi afetada por outro evento extensional, relacionado à separação entre a América do Sul e a África, quando depressões foram preenchidas por rochas sedimentares e vulcânicas. Na Bacia dos Parecis este evento corresponde aos derrames basálticos das formações Anari e Tapirapuã, que ocorreram em torno de 198Ma., os quais foram cobertos, em tempo muito próximo ou concomitante aos derrames, pelos arenitos de origem eólica da Formação Rio Ávila. No Cretáceo foi depositado o Grupo Parecis, composto de conglomerados e arenitos, depositada em ambientes fluvial e eólico.

A intepretação dos mapas gravimétricos da Bacia dos Parecis indica um baixo gravimétrico na porção leste da bacia, o qual foi denominado por Siqueira (1989) Sub-bacia de Rondônia ou Fossa Tectônica de Rondônia. Esta depressão muito profunda, em torno de $6 \mathrm{~km}$, corresponde aos grabens de Pimenta Bueno e do Colorado, os quais se estendem por mais de $700 \mathrm{~km}$ para leste, abaixo das sub-bacias Juruena e Alto Xingu.

O Mapa da Segunda Derivada Vertical do campo gravitacional da Bacia dos Parecis mostra uma perfeita seqüência de altos e baixos estruturais, alinhados segundo uma estruturação NW-SE, correspondendo aos grabens do Colorado, Pimenta Bueno, Noroeste do Rio Xingu e Sudoeste do Rio Xingu.

A modelagem gravimétrica na Bacia dos Parecis forneceu resultados interessantes sobre a arquitetura crustal na região da bacia. As seções crustais permitiram verificar a configuração da descontinuidade de Moho, segundo um acamadamento espacial típico de uma crosta interior rifteada, coberta por uma espessa camada sedimentar, a qual foi precursora da Bacia dos Parecis, onde a descontinuidade de Moho atinge 40km de profundidade. No restante da bacia a interface crosta-manto apresenta-se levemente ondulada, com profundidade média em torno de $30 \mathrm{~km}$. Esta configuração 
deve-se possivelmente ao afinamento crustal/litosférico e elevação da astenosfera, conseqüentes dos processos de rifteamento.

\section{Referências}

Almeida F.F.M.1983. Relações tectônicas das rochas alcalinas mesozóicas da região meridional da Plataforma SulAmericana. Rev. Bras. de Geociências, 13:139-158.

Bahia R.B.C. \& Pedreira A.J.1996. Depósitos glaciogênicos da Formação Pimenta Bueno (Carbonífero) na região de Rolim de Moura, sudeste de Rondônia. A Terra em Revista, 1:24-29.

Barros A.M. \& Pastore Júnior W.P. 1974. Projeto Alto Guaporé. Relatório final. Folha Tangará da Serra-SD.21Y-B. DNPM/CPRM, Goiânia, 11 v.

Braga L.F.S. \& Siqueira L.P. 1996. Three dimensional gravity modelling of the basement topography beneath Parecis Basin, Brazil, constrained by spectral estimates of depth to magnetic sources. In: CONNEXPO/ARPEL, Latin American Petroleum Congress, 5, Atas, p. 8.

Brito Neves B.B. \& Cordani U.G. 1991. Tectonic evolution of South America during the late Proteroic. Precambrian Research, 53:23-40.

Brito Neves B.B. de, Sá J.M. de, Nilson A.A., Botelho N.F. 1995. A Tafrogênese estateriana nos blocos paleoproterozóicos da América do Sul e processos subseqüentes. Geonomos, 3(2):1-21.

Brito Neves B.B., Fuck R.A., Cordani U.G., Tomaz Francisco A. 1984. Influence of basement structures on the evolution of the major sedimentary basins of Brazil: a case of tectonic heritage. Journal of Geodynamics, 1:495-510.

Caputo M.V. 1984. Stratigraphy, tectonics, paleoclimatology and paleography of the northern basins of Brazil. Tese de Doutoramento, University of California, 533 p.

Costa S.A.G., Fragomeni P.R.P., Fragomeni M.G. 1975. Projeto Serra do Roncador. Reconhecimento geológico. Relatório final. DNPM/CPRM, Goiânia, 3 v.

Figueiredo A.J. de A., Barros A.M., Eulálio Filho A., Rodrigues A.P., Barreto B.F., Pimentel G.B., Couto J.G.P., Reischl J.L., Costa S.A.G., Resende Filho S.T., Pastore Júnior W.P., Ribeiro Filho W. 1974. Projeto Alto Guaporé. Relatório final. CPRM, Goiânia, 11 v.

Kingston D.R., Dishroon C.P., Williams P.A. 1983. Global basin classification system. American Association of Petroleum Geologists Bulletin, 67:2175-2193.

Leal J.W., Silva G.F., Santos D.B. dos, Teixeira W., Lima M.I.C. de, Fernandes A.C., Pinto A. do C. 1978. Geologia. In: BRASIL. DNPM. Folha SC.20 Porto Velho; geologia, geomorfologia, pedologia, vegetação e uso potencial da terra. Rio de Janeiro, Projeto RADAMBRASIL, 662 p. (Levantamento de Recursos Naturais, 16) p. 17-184.

Marzoli A., Renne P.R., Piccirillo E.M., Ernesto M. Bellieni, Min A.D.,1999. Extensive 200-million-year-old continental flood basalts of the Central Atlantic Magmatic Province. Science, 284:616-618.

Milani E.J. 1997. Evolução tectono-estratigráfica da bacia do Paraná e seu relacionamento com a geodinâmica fa- nerozóica do Gondwana Sul-Ocidental. Tese de Doutoramento, Instituto de Geociências, Universidade Federal do Rio Grande do Sul, 255 p.

Neves B.B.B. \& Cordani U.G. 1991. Tectonic evolution of South America during the late Proterozoic. Precambrian Research, 53:23-40.

Neves B.B.B. et al. 1984. Influence of basement structures on the evolution of the major sedimentary basins of Brazil : a case of tectonic heritage. Journal of Geodynamics, 1:495-510.

Padilha A.V. 1974. Projeto Centro-Oeste de Mato Grosso. Relatório final. DNPM/CPRM, Goiânia, v. 1.

Pedreira A.J. 1998. Sistemas deposicionais e estratigrafia da Bacia dos Parecis no Estado de Rondônia. CPRM, Salvador, $32 \mathrm{p}$.

Pinto Filho F.P., Freitas A.F. de, Melo C.F. de, Romanini S.J. 1977. Projeto Sudeste de Rondônia. Relatório Final. DNPM/CPRM, Porto Velho, 4 v.

Ribeiro Filho W., Luz, J.S., Abreu Filho W. 1975. Projeto Serra Azul. Reconhecimento geológico. Relatório final. DNPM/CPRM, Goiânia, V. 1.

Santos R.D.B. 1979. Geologia. In: Brasil. DNPMFolha SD. 20 Guaporé; geologia, geomorfologia, pedologia, vegetação e uso potencial da terra. Rio de Janeiro, Projeto RADAMBRASIL, 364 p. (Levantamento de Recursos Naturais, 19) p. 21-123.

Scandolara J.E.(org.) 1997. Mapa geológico do Estado de Rondônia. Escala 1:1.000.000. CPRM/REPO, Porto Velho (Versão preliminar).

Schobbenhaus C., Campos D. de A., Derze G.R., Asmus H.E. (eds.) 1984. Geologia do Brasil; texto explicativo do mapa geológico do Brasil e da área oceânica adjacente incluindo depósitos minerais. MME/DNPM, Brasília. $501 \mathrm{p}$.

Siqueira L.P. 1989. Bacia dos Parecis. Boletim de Geociências da Petrobrás, 3:3-16.

Siqueira L.P. \& Teixeira L.B. 1993. Bacia dos Parecis: nova fronteira exploratória da Petrobrás. In: SBGeof., Congr. Intern. Soc. Brás. Geof., 3, Resumos Expandidos, p.168170.

Soeiro R.S. 1981. Projeto Prospecção de Carvão Energético em Rondônia. Relatório final. DNPM/CPRM, Porto Velho.

Tassinari C.C.G. \& Macambira M.J.B. 1999. Geochronological province of the Amazonian Craton. Episodes, 22 (3):174-182.

Vidotti R.M., Ebinger C.J., Fairhead J.D. 1998. Gravity signature of the western Paraná Basin, Brazil. Earth and Planetary Science Letters, 139:117-132.

Manuscrito AE-032/2006

Submetido em 03 de agosto de 2006 Aceito em 05 de março de 2007 